\title{
Difficulty Obtaining Behavioral Health Services for Children: A National Survey of Multiphysician Practices
}

\author{
Alyna T. Chien, $M D, M S^{1,2}$ \\ JoAnna Leyenaar, $M D, P b D, M P H^{3,4}$ \\ Marisa Tomaino ${ }^{4}$ \\ Steven Woloshin, MD, MS $S^{4,5}$ \\ Lindsey Leininger, $\mathrm{PbD}^{4}$ \\ Erin R. Barnett, $P b D^{4,6}$ \\ Jennifer L. McLaren, $M D^{4,6}$ \\ Ellen Meara, $P b D^{4,7,8}$ \\ 'Division of General Pediatrics, Depart- \\ ment of General Pediatrics, Boston Chil- \\ dren's Hospital, Boston, Massachusetts \\ ${ }^{2}$ Department of Pediatrics, Harvard Medical \\ School, Boston, Massachusetts \\ ${ }^{3}$ Department of Pediatrics, Dartmouth-Hitch- \\ cock Medical Center, Lebanon, New Hampshire \\ ${ }^{4}$ The Dartmouth Institute for Health Policy \& \\ Clinical Practice, Lebanon, New Hampshire \\ ${ }^{5}$ The Lisa Schwartz Foundation for Truth \\ in Medicine, Norwich, Vermont \\ ${ }^{6}$ Department of Psychiatry, Dartmouth-Hitch- \\ cock Medical Center, Lebanon, New Hampshire \\ ${ }^{7}$ National Bureau of Economic Research, \\ Cambridge, Massachusetts \\ ${ }^{8}$ Harvard T.H. Chan School of Public Health, \\ Boston, Massachusetts
}

Conflicts of interest: authors report none.

\section{CORRESPONDING AUTHOR}

Alyna T. Chien

Division of General Pediatrics

Boston Children's Hospital

300 Longwood Avenue

Boston, MA 02115

alyna.chien@childrens.harvard.edu

\begin{abstract}
PURPOSE In the United States, primary care practices rely on scarce resources to deliver evidence-based care for children with behavioral health disorders such as depression, anxiety, other mental illness, or substance use disorders. We estimated the proportion of practices that have difficulty accessing these resources and whether practices owned by a health system or participating in Medicaid accountable care organizations (ACOs) report less difficulty.
\end{abstract}

METHODS This national cross-sectional study examined how difficult it is for practices to obtain pediatric (1) medication advice, (2) evidence-based psychotherapy, and (3) familybased therapy. We used the National Survey of Healthcare Organizations and Systems 2017-2018 (46.9\% response rate), which sampled multiphysician primary and multispecialty care practices including 1,410 practices that care for children. We characterized practices' experience as "difficult" relative to "not at all difficult" using a 4-point ordinal scale. We used mixed-effects generalized linear models to estimate differences comparing systemowned vs independent practices and Medicaid ACO participants vs nonparticipants, adjusting for practice attributes.

RESULTS More than $85 \%$ of practices found it difficult to obtain help with evidence-based elements of pediatric behavioral health care. Adjusting for practice attributes, the percent experiencing difficulty was similar between system-owned and independent practices but was less for Medicaid ACO participants for medication advice ( $81 \%$ vs $89 \% ; P=.021)$ and evidence-based psychotherapy ( $81 \%$ vs $90 \% ; P=.006)$; differences were not significant for family-based treatment $(85 \%$ vs $91 \% ; P=.107)$.

CONCLUSIONS Most multiphysician practices struggle to obtain advice and services for child behavioral health needs, which are increasing nationally. Future studies should investigate the source of observed associations.

Ann Fam Med 2022;20:42-50. https://doi.org/10.1370/afm.2759.

\section{INTRODUCTION}

I $\mathrm{n}$ the United States, behavioral health problems such as depression, anxiety, other mental illness, or substance use disorders are increasing among children, and this trend is expected to extend beyond the COVID-19 pandemic. ${ }^{1-9}$ When used appropriately, psychotropic drugs, evidence-based psychotherapy, and familybased treatments are cornerstones of effective treatment ${ }^{10.13}$ but are challenging to deliver broadly given the ongoing national shortage of child behavioral health professionals. ${ }^{14-16}$ Primary care practices are at the frontline of delivering pediatric behavioral health services because they provide a familiar, nonstigmatizing context in which behavioral health issues can gain attention. ${ }^{1,17,18}$

Several randomized trials and systematic reviews found that primary care practices can deliver high-quality, evidence-based behavioral health care for children if practices establish collaborative relationships with behavioral health professionals (psychiatrists, psychologists, therapists) or formally integrate such experts into their practices. ${ }^{19-21}$ However, we do not know how easily practices can cultivate such relationships outside of participating in a clinical trial. ${ }^{20,22-28}$ According to the latest nationally representative survey on this issue, completed in 2004-2005, two-thirds $(67 \%)$ of primary care physicians reported being unable to obtain high-quality outpatient mental health services for their patients, ${ }^{29}$ but that survey did not distinguish child from adult behavioral health services. ${ }^{29}$

Meanwhile, physician practices have been undergoing dramatic changes in organization that might have put behavioral health personnel in closer 
organizational proximity to primary care physicians. Practices have grown in size, adopted team-based models of care, ${ }^{30-32}$ joined other practices, or have been bought by health systems. ${ }^{33-35}$ Today more than in the past, primary care practices are more likely to belong to larger organizations that might, in theory, directly employ clinicians with behavioral health expertise or have other types of clinicians (eg, patient navigators) who can help obtain behavioral health services for patients when needed.

Contemporaneously, practices have been engaging in alternative payment models that might support practices' efforts to test new models of care, especially those that prioritize ongoing management of chronic conditions over that for acute, self-limited disease. ${ }^{36}$ Such payment models can benefit patients with behavioral health conditions directly if behavioral health conditions are of focus within contracts (eg, Medicaid accountable care organization $[\mathrm{ACO}]$ contracts $)^{37,38}$ or indirectly via more general practice improvements (eg, the Centers for Medicare and Medicaid Services' [CMS] Comprehensive Primary Care Plus [CPC+] programs) ${ }^{39}$ Although alternative payment models tend to be designed with adults in mind, adult-oriented, value-based ventures can have positive spillover effects on pediatric care quality. ${ }^{40-43}$ If practices are striving to improve, their pediatric care might improve too.

We hypothesized that most practices in the United States find it difficult to obtain the behavioral health advice and services needed to care for children with behavioral health disorders and that practices owned by health systems and practices participating in alternative payment models might report less difficulty obtaining this care.

\section{METHODS}

\section{Study Design and Data Sources}

This national cross-sectional study focused on 1,410 multiphysician primary and multispecialty care practices that cared for children and responded to the 2017-2018 National Survey of Healthcare Organizations and Systems (NSHOS) questions regarding difficulty obtaining services for children with behavioral health service needs. ${ }^{44,45}$ The NSHOS drew a stratified random sample of physician practices from IQVIA's OneKey database, a repository of US physicians, practices, hospitals, and systems and the ownership relationships among these entities. ${ }^{46,47}$ Multiphysician practices were defined as those with $\geq 3$ primary care physicians (family medicine, internal medicine, geriatrics, general practitioner). The NSHOS posed questions about practices' organizational structures, capabilities, and care processes using multiple modes (mail, telephone, Internet) to reach leaders within practices. Respondents were medical directors, physician managers, and practice managers. Of the 4,976 practices that the NSHOS sampled, 2,333 (46.9\%) responded, and 2,190 $(44.3 \%)$ were confirmed as being in the sample frame-multiphysician primary care or multispecialty practices with at least 3 primary care physicians (general practice, family practice, internal medicine, or geriatrics). ${ }^{44,45}$ We included 1,410 multiphysician primary and multispecialty care practices that answered all 3 child-related behavioral health questions, had information available on Medicaid ACO contract participation, had a zip code that could be mapped to rural-urban commuting areas, and had an ownership relationship that fit our ownership categories. ${ }^{44-46}$ Supplemental Appendix 1 presents additional information on practice sample selection and item nonresponse. This study was approved by Dartmouth College's Committee on the Protection of Human Subjects, which waived documentation for informed consent.

\section{Primary Outcomes}

After presenting respondents with a definition of behavioral health ("behavioral health includes depression, anxiety, other mental illness, or substance use disorders"), the NSHOS asked practice leaders, "How difficult is it to obtain: (i) medication advice from a child psychiatrist or psychiatric nurse practitioner; (ii) evidence-based psychotherapy; and (iii) family-based treatment?" Responses of "very difficult," "somewhat difficult," and "slightly difficult" were characterized as "difficult" relative to "not at all difficult" after the distribution of responses was reviewed.

\section{Practice Attributes}

Supplemental Appendix 2 presents detailed variable definitions and sources for each practice attribute below.

\section{System vs Independent Practice Ownership}

Because in theory, system-owned practices might have access to a larger network of pediatric behavioral health professionals either within the practice itself or at other practices within the same system, we evaluated how system ownership was associated with our primary outcomes. As in prior research, ${ }^{48}$ we used the OneKey database to classify practice ownership into the following 4 mutually exclusive types: (1) independent practices, with no ownership relationships beyond the practice itself, (2) medical group practices, owned by an organization that owns $\geq 2$ practices but no hospital, (3) simple system practices, owned by an organization that owns practices and $\geq 1$ hospital, and (4) complex system practices, owned by an organization that itself owns $\geq 1$ medical group or system (ie, a system within a system). Practices were considered system owned if they were owned by medical groups, simple systems, or complex systems; otherwise practices were considered independent.

\section{Practice Size and Workforce}

We used OneKey data to determine practice size (total number of clinicians, total number of physicians) and physician specialty. We achieved this by mapping National Provider Identifiers to a taxonomy based on the American Board of Medical Specialties. We identified the following 3 groups of physicians, each with slightly different training related to 
pediatric behavioral health: (1) primary care physicians who are trained in pediatrics and frequently care for patients aged 0-18 years (family medicine practitioners, obstetrician-gynecologists, medicine-pediatrics physicians), (2) general and child psychiatrists, and (3) general and specialty pediatricians (who are trained to identify and manage child behavioral health issues). The total number of nonphysician clinicians (nurse practitioners, physician assistants, licensed social workers) could be counted, but we lacked the necessary information to further define their roles in practices as being directed toward behavioral health.

\section{Orientation Toward Socioeconomically At-Risk Patient Populations}

Because practices that serve a large share of socioeconomically at-risk patients can develop clinical expertise in the care of children with behavioral health conditions and corresponding infrastructures and workflows, we used the NSHOS to characterize practices' revenue sources (percentage of total annual practice revenue coming from commercial payers, Medicare, Medicaid, or other sources [eg, self-pay]), whether revenue from Medicaid was in the top quartile (ie, $>25 \%$ ) across practices, whether a practice had federally qualified health center (FQHC) or FQHC look-alike status, and whether a practice was located in a rural zip code (using the rural-urban commuting area classification method). ${ }^{49}$

\section{Participation in Payment or Delivery Reform Initiatives}

The NSHOS asked, "Has your practice ever participated in any of these payment and delivery reform initiatives?" Practices were provided the following list of options: primary care improvement and support programs, pay for performance programs, capitated contracts with commercial health plans, Medicaid ACO contracts, and commercial ACO contracts If practices answered, "Yes, currently" we counted them as participating in the corresponding initiative, and placed those answering "Yes, previously but not now" or "No, never" in the reference group. CMS CPC+ participation was ascertained by linking respondents of the NSHOS survey to participant lists published by $\mathrm{CMS}_{\text {; }}$ both lists share practice attributes (eg, name, location, etc). ${ }^{50}$

\section{Statistical Analysis}

We used descriptive statistics to describe the distribution of practice attributes across the 4 practice ownership types (Table 1). For unadjusted analyses, significant differences across ownership types were determined using F-statistics for continuous variables and $\chi^{2}$ tests for categorical variables, setting significance at $P<.05$.

We estimated the adjusted percent of practices reporting difficulty obtaining services for children with behavioral health disorders. Separately, for each behavioral health service examined, we fit mixed-effects generalized linear models (ie, linear probability models) estimating whether a practice reported difficulty obtaining that service as a function of practice ownership type (medical group, simple system, complex system vs independent) and practice participation in a Medicaid ACO. Models controlled for practice size, CPC+ program participation, orientation toward socioeconomically at-risk populations, and practice workforce characteristics as specified in Table 2. Models also included an indicator for the state in which a practice is located, to account for underlying state-bystate differences in behavioral health resources and Medicaid state policies. ${ }^{51,52}$ To account for the hierarchical nature of the data (practices are nested within systems), models included a random intercept for each health system (or medical group). All estimates were weighted to be representative of the stratified sample frame and to account for survey nonresponse. ${ }^{47}$ We performed our analyses using Stata 15 (StataCorp LLC). For ease of presentation, we also used estimates from the models described above to compare adjusted outcomes for all system-owned practice types combined (medical group, simple, or complex system) to independent practices.

\section{RESULTS}

\section{Practice Attributes}

Of the multiphysician practices caring for children, $26.0 \%$ were independent practices, $17.4 \%$ belonged to medical groups, $15.8 \%$ were members of simple systems, and $40.8 \%$ were members of complex systems (Table 1). For almost all attributes examined, system-owned practices differed significantly from independent practices. System-owned practices (medical group, simple, or complex) tended to be larger, more likely to employ psychiatrists and general pediatricians, and more likely to participate in a delivery or payment reform initiative. Independent practices and simple systems were more likely to receive large shares of revenue from Medicaid (ie, top quartile across practices), to be located in rural zip codes, and to be located in the South. The percent of practices with any pediatric-trained primary care physicians did not differ significantly by ownership type. There appeared to be more differences among system-owned practices than between systemowned practices relative to independent ones with respect to annual practice revenues from commercially insured sources and practice locations in the Northeast and West.

\section{Difficulties Obtaining Psychiatric Advice and Related Behavioral Health Services}

Adjusting for the practice characteristics shown in Table 2, most practices $(>85 \%)$ found it difficult to obtain pediatric behavioral health services, regardless of service type (Figure 1; Supplemental Appendix 3). The percent experiencing difficulty did not differ significantly between system-owned and independent practices, but practices participating in a Medicaid $\mathrm{ACO}$ reported less difficulty obtaining medication advice $(80.5 \%$ vs $89.3 \% ; P=.021)$ and evidence-based psychotherapy $(81.0 \%$ vs $90.4 \% ; P=.006)$; the difference was not significant for family-based treatment $(85.1 \%$ vs $90.6 \% ; P=.107)$. 
Table 1. Practice Attributes by Ownership Structure

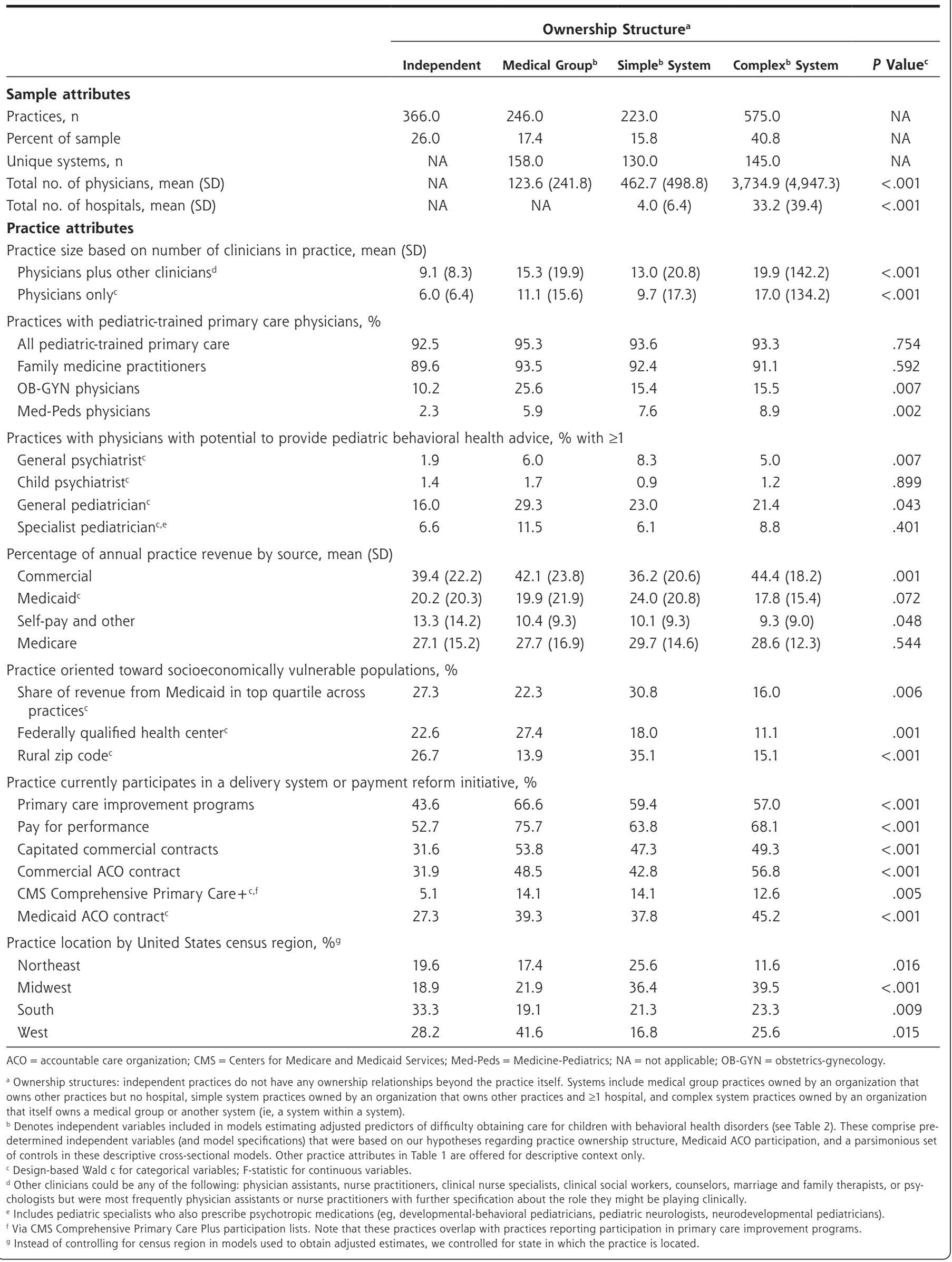


Table 2. Adjusted Percentage-Point Difference Compared With Referent in Difficulty Obtaining Pediatric Behavioral Health Advice and Services

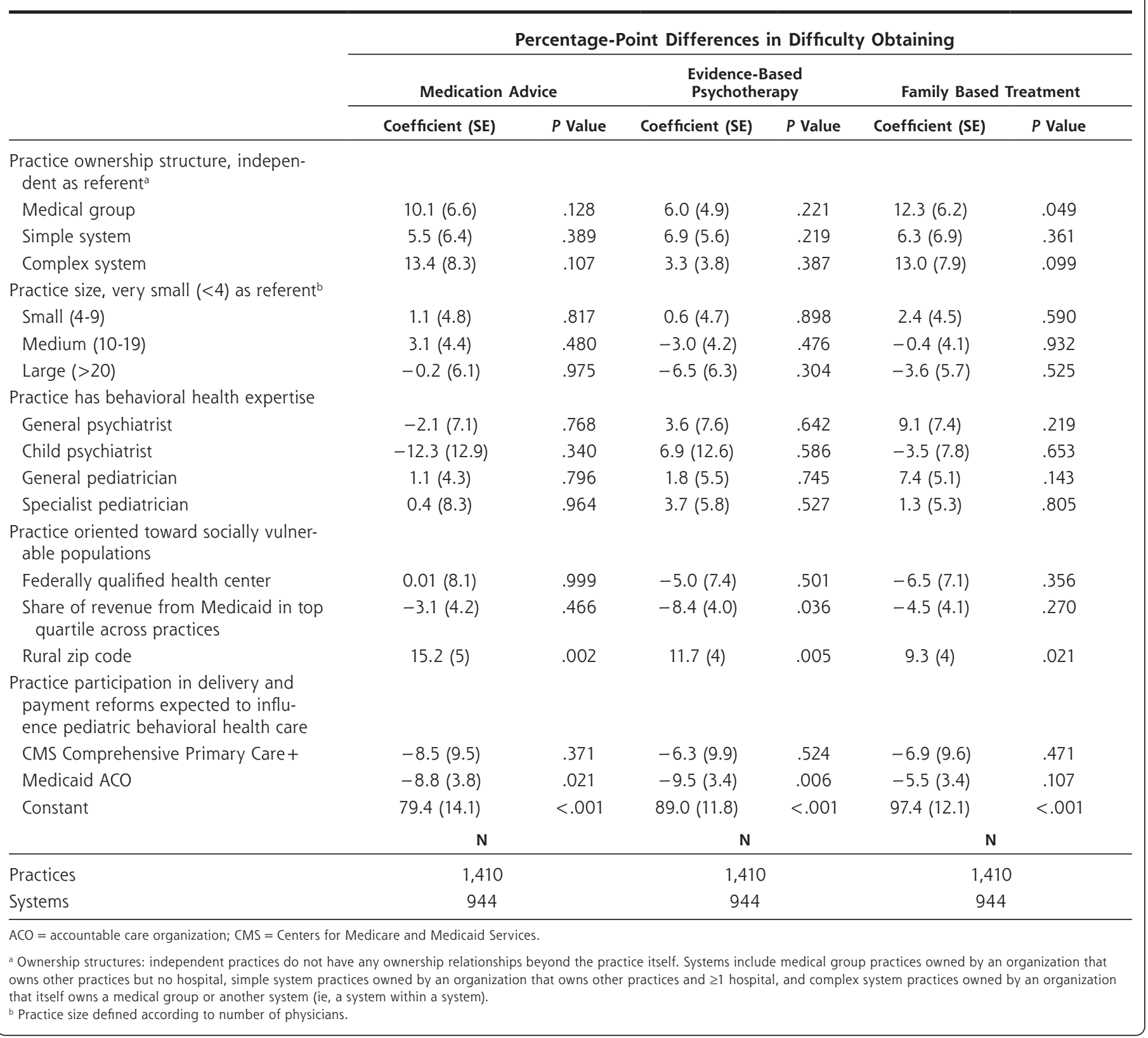

In multivariate models including the attributes shown in Table 2, the presence of behavioral health expertise within practices showed no significant associations with difficulty obtaining pediatric behavioral health medication advice or related services. Similarly, participants in $\mathrm{CMS}^{\prime} \mathrm{CPC}_{+}$, an alternative payment model targeting primary care practices, were no less likely to have difficulty obtaining such services

Notably, in adjusted analyses, practices in rural locations had significantly greater difficulty obtaining pediatric behavioral health advice and related services relative to their nonrural counterparts. These practices were more likely to have difficulty obtaining all 3 types of behavioral health services examined-medication advice, evidence-based psychotherapy, and family-based treatment by $+15.2(P=.002)$, $+11.7(P=.005)$, and $+9.3(P=.021)$ percentage points, respectively (Table 2 ). Lastly, relative to independent practices, medical group practices were more likely to have difficulty obtaining family-based treatment by +12.3 percentage points $(P=.049)$.

\section{DISCUSSION}

In this nationally representative sample of multiphysician practices in the United States, practice leaders rated how difficult 
Figure 1. Difficulty obtaining pediatric behavioral health services, by service type.
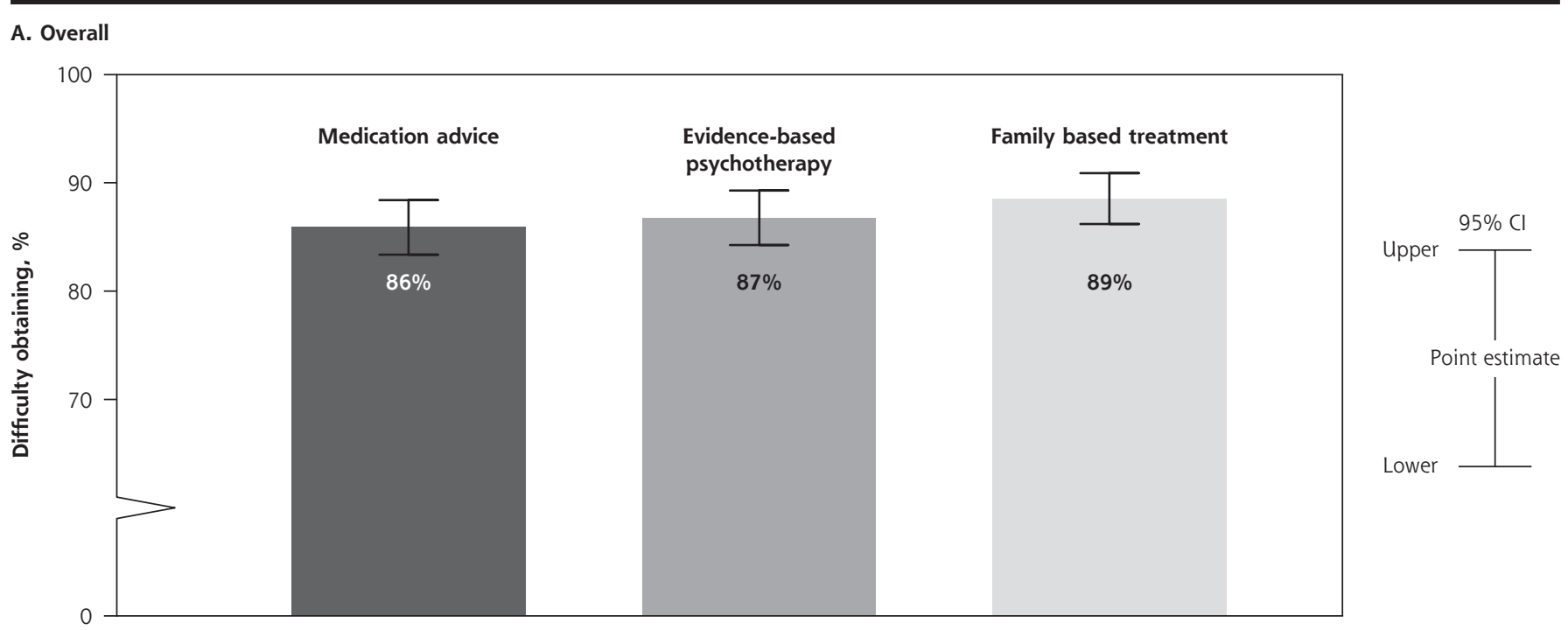

B. Ownership structure

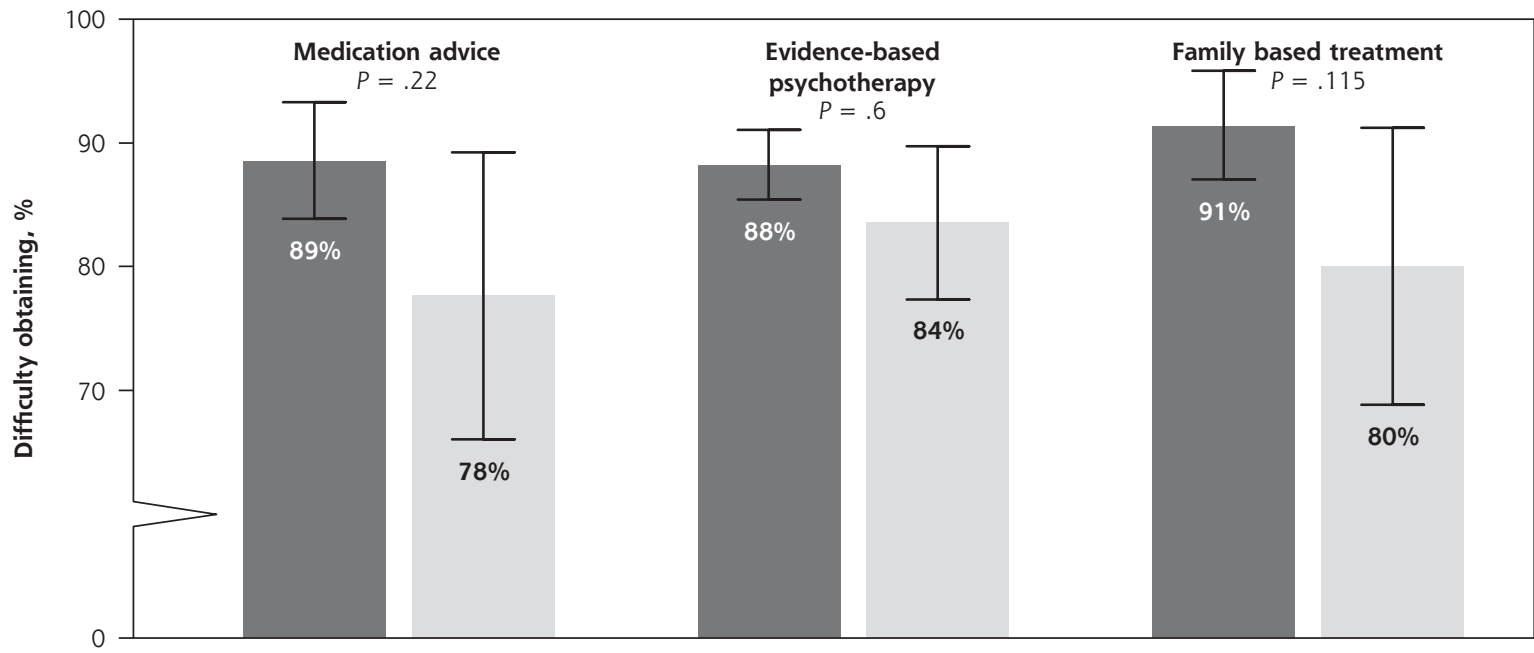

In system?

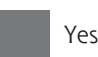

C. Participation in Medicaid accountable care organization contract

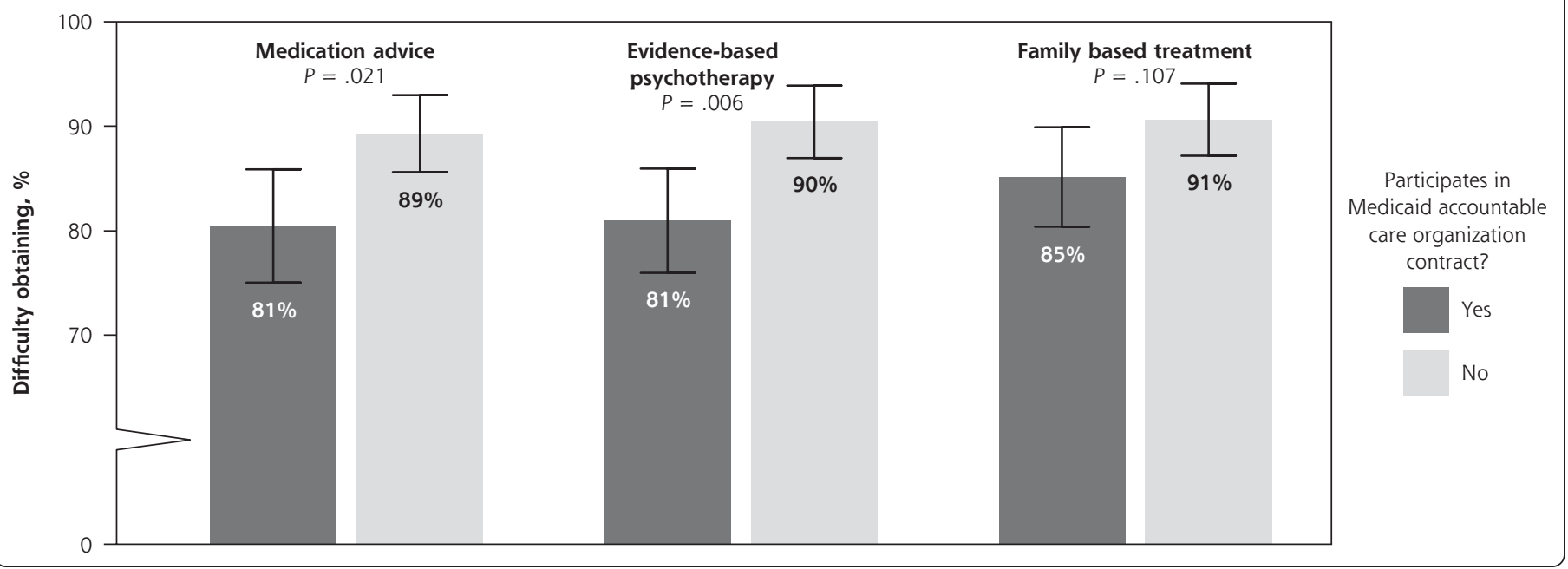


it was for their practices to obtain the advice and services needed to deliver evidence-based treatment for children with behavioral health disorders. We document 3 main findings.

First, most practices-more than $85 \%$ - reported difficulty obtaining help caring for pediatric behavioral health conditions. ${ }^{19-21}$ This exceeds the $67 \%$ noted in the most recent comparable study based on a 2004-2005 survey; however, the 2004-2005 study did not distinguish child from adult behavioral health services. ${ }^{29}$ The present finding is concerning because rates of childhood anxiety, depression, self-injurious behavior, and suicide were already increasing before the current COVID-19 pandemic, which has exacerbated this preexisting trend. ${ }^{1-9}$ The difficulty levels also varied in an expected way; given the scarcity of child behavioral health professionals, it makes sense that delivering evidencebased treatments and family-based therapy might be viewed as more difficult to obtain than medication advice. ${ }^{14-16}$ Despite advances in our understanding of the biologic basis of behavioral health conditions, improved treatments, and federal legislation designed to expand access to behavioral health care (eg, the Mental Health Parity and Addiction Equity Act of 2008; the Patient Proection and Affordable Care Act of 2010), significant barriers to behavioral health treatment remain. For example, behavioral health experts are still scarce, and treatments are often unaffordable. ${ }^{53}$ If primary care practices are to fulfill their role as the nation's frontline for identifying and treating or referring patients with pediatric behavioral health disorders, the present study finds practices in clear need of collaborative or integrative relationships with behavioral health experts.

Second, we found that system-owned practices fared no better than independent practices in terms of the difficulty they experience in obtaining pediatric behavioral health advice and services. Even though system-owned practices are far larger and more likely to have personnel (eg, psychiatrists, nurse practitioners, physician assistants) who could serve as behavioral health resources, the present study does not support the notion that ownership alone can extend the reach of scarce behavioral health resources to the primary care frontline. Future studies should examine whether these associations change as new organizational forms mature to develop integrative or collaborative behavioral health service models.

Third, comparing otherwise similar practices, Medicaid ACO participants reported less difficulty than nonparticipants in obtaining needed services. This finding warrants further investigation to understand whether joining a Medicaid ACO can cause this type of change, or whether organizations are better equipped to link children to needed services for other reasons. It could be that Medicaid ACO contract participation merely reflects how attuned practices are to the behavioral health needs of their patient populations rather than facilitating the creation of collaborative or integrative relationships needed to deliver behavioral health care. ${ }^{37}$ Early evidence suggests that all of the above are possible, ${ }^{54-56}$ but more empirical work is necessary to understand this finding.
The present study has several limitations. First, the main outcome was a self-reported measure from practice managers, and it might not reflect how frontline clinicians would rate their experiences. However, the practice perspective is important for prioritizing practice-wide clinical quality improvement efforts. Second, we assessed a single cross-section in time (2017-2018), however, these years are critically important from a payment reform perspective-they capture the timeframe in which Medicaid-sponsored ACO efforts started proliferating and follow after 5 to 10 years of experience with primary-care-focused alternative payment models sponsored by commercial payers and Medicare. ${ }^{57-59}$ Third, although the sample frame of multiphysician primary care or multispecialty practices did not include physician practices focused on pediatrics, the results remind us of how frequently family medicine physicians care for children, especially as they enter adolescence. ${ }^{60}$ Fourth, limited power to detect effects might have obscured greater difficulty obtaining care by complex system practices compared with independent practices. Fifth, in this cross-sectional study, observed associations could reflect unobserved confounding (eg, practice finances). Still, this national study provides a rare but important glimpse into the services being provided to pediatric patients by family medicine physicians in the United States. Going forward, it is important to appreciate the crucial role that diverse multispecialty primary care practices play in caring for children, especially in rurally located practices.

In summary, this first-of-its-kind study set in the United States offers a glimpse into the accessibility of clinical care for children's behavioral health as American health care undergoes broad changes in structure and incentives. The news is sobering - the challenge of providing behavioral health treatments for children is a hefty one, and much progress needs to be made.

Read or post commentaries in response to this article.

Key words: accountable care organizations; behavior; child; psychotherapy; therapeutics; Medicaid; pediatrics; primary health care

Submitted December 17, 2020; submitted, revised, May 21, 2021; accepted June 21, 2021.

Funding support: This study was funded by the Agency for Healthcare Research and Quality U19 HS024075-05 (principal investigator: E. Meara).

Disclaimer: The statements, findings, conclusions, views, and opinions contained and expressed in this article are based in part on data obtained under license from IQVIA information services (OneKey subscription information services 201018; IQVIA Inc; all rights reserved). The statements, findings, conclusions, views, and opinions contained and expressed herein are not necessarily those of IQVIA Inc or any of its affiliated or subsidiary entities. The American Medical Association (AMA) was the source for the raw physician data; statistics, tables, and tabulations were prepared by the authors using data from the AMA Physician Masterfile.

Previous presentation: This study was presented at The Dartmouth Institute's U19 Center of Excellence on Comparative Health System Performance; November, 2019; Lebanon, New Hampshire.

Acknowledgments: This paper is dedicated to the memory of Lisa Schwartz, MD, MS, our remarkable partner, colleague, and friend who proposed this research. Dr Schwartz died before publication of this article.

\section{Supplemental materials}




\section{References}

1. Merikangas KR, He JP, Burstein M, et al. Service utilization for lifetime mental disorders in U.S. adolescents: results of the National Comorbidity SurveyAdolescent Supplement (NCS-A). J Am Acad Child Adolesc Psychiatry. 2011; 50(1):32-45. 10.1016/j.jaac.2010.10.006

2. Xu G, Strathearn L, Liu B, Yang B, Bao W. Twenty-year trends in diagnosed attention-deficit/hyperactivity disorder among US children and adolescents, 1997-2016. JAMA Netw Open. 2018;1(4):e181471. 10.1001/ jamanetworkopen.2018.1471

3. Mojtabai R, Olfson M, Han B. National trends in the prevalence and treatment of depression in adolescents and young adults. Pediatrics. $2016 ; 138(6)$ : e20161878. 10.1542/peds.2016-1878

4. Mercado MC, Holland K, Leemis RW, Stone DM, Wang J. Trends in emergency department visits for nonfatal self-inflicted injuries among youth aged 10 to 24 years in the United States, 2001-2015. JAMA. 2017:318(19):19311933. 10.1001/jama.2017.13317

5. Miron O, Yu KH, Wilf-Miron R, Kohane IS. Suicide rates among adolescents and young adults in the United States, 2000-2017. JAMA. 2019;321(23): 2362-2364. 10.1001/jama.2019.5054

6. Curtin SC, Heron M. Death rates due to suicide and homicide among persons aged 10-24: United States, 2000-2017. NCHS Data Brief. 2019;(352):1-8.

7. Mishara BL, Stijelja S. Trends in US suicide deaths, 1999 to 2017, in the context of suicide prevention legislation. JAMA Pediatr. 2020;174(5):499-500. 10.1001/jamapediatrics.2019.6066

8. Hedegaard H, Curtin SC, Warner M. Increase in suicide mortality in the United States, 1999-2018. NCHS Data Brief. 2020;(362):1-8.

9. Patrick SW, Henkhaus LE, Zickafoose JS, et al. Well-being of parents and children during the COVID-19 pandemic: a national survey. Pediatrics. 2020; 146(4):e2020016824. 10.1542/peds.2020-016824

10. March JS, Silva S, Petrycki S, et al. The Treatment for Adolescents With Depression Study (TADS): long-term effectiveness and safety outcomes. Arch Gen Psychiatry. 2007;64(10):1132-1143. 10.1001/archpsyc.64.10.1132

11. Cox GR, Callahan P, Churchill R, et al. Psychological therapies versus antidepressant medication, alone and in combination for depression in children and adolescents. Cochrane Database Syst Rev. 2012;11:CD008324. 10.1002/14651858.CD008324.pub2

12. Asarnow JR, Rozenman MS, Carlson GA. Medication and cognitive behavioral therapy for pediatric anxiety disorders: no need for anxiety in treating anxiety. JAMA Pediatr. 2017;171(11):1038-1039. 10.1001/ jamapediatrics.2017.3017

13. Wang Z, Whiteside SPH, Sim L, et al. Comparative effectiveness and safety of cognitive behavioral therapy and pharmacotherapy for childhood anxiety disorders: a systematic review and meta-analysis. JAMA Pediatr. 2017;171(11): 1049-1056. 10.1001/jamapediatrics.2017.3036

14. Health Resources and Services Administration Health Workforce. Behavioral health workforce projections, 2016-2030: psychiatrists (adult), child and adolescent psychiatrists. Published 2019. Accessed Oct 26, 2021. https:// bhw.hrsa.gov/sites/default/files/bureau-health-workforce/data-research/ psychiatrists-2018.pdf

15. Axelson D. Meeting the demand for pediatric mental health care. Pediatrics. 2019;144(6):e20192646. 10.1542/peds.2019-2646

16. McBain RK, Kofner A, Stein BD, Cantor JH, Vogt WB, Yu H. Growth and distribution of child psychiatrists in the United States: 2007-2016. Pediatrics. 2019;144(6):e20191576. 10.1542/peds.2019-1576

17. Olfson M, Blanco C, Wang S, Laje G, Correll CU. National trends in the mental health care of children, adolescents, and adults by office-based physicians. JAMA Psychiatry. 2014;71(1):81-90. 10.1001/jamapsychiatry.2013.3074

18. Ghandour RM, Sherman LJ, Vladutiu CJ, et al. Prevalence and treatment of depression, anxiety, and conduct problems in US children. J Pediatr. 2019; 206:256-267.e3. 10.1016/j.jpeds.2018.09.021

19. Burns BJ, Burke JD Jr. Improving mental health practices in primary care: findings from recent research. Public Health Rep. 1985;100(3):294-300.

20. Asarnow JR, Rozenman M, Wiblin J, Zeltzer L. Integrated medical-behavioral care compared with usual primary care for child and adolescent behavioral health: a meta-analysis. JAMA Pediatr. 2015;169(10):929-937. 10.1001/ jamapediatrics.2015.1141
21. Asarnow JR, Jaycox LH, Duan N, et al. Effectiveness of a quality improvement intervention for adolescent depression in primary care clinics: a randomized controlled trial. JAMA. 2005;293(3):311-319. 10.1001/jama.293.3.311

22. Blount A. Integrated primary care: organizing the evidence. Fam Syst Health. 2003;21(2):121-133. 10.1037/1091-7527.21.2.121

23. Gilbody S, Bower P, Fletcher J, Richards D, Sutton AJ. Collaborative care for depression: a cumulative meta-analysis and review of longer-term outcomes. Arch Intern Med. 2006;166(21):2314-2321. 10.1001/archinte.166.21.2314

24. Williams JW Jr, Gerrity M, Holsinger T, Dobscha S, Gaynes B, Dietrich A. Systematic review of multifaceted interventions to improve depression care. Gen Hosp Psychiatry. 2007;29(2):91-116. 10.1016/j.genhosppsych.2006.12.003

25. Butler M, Kane RL, McAlpine D, et al. Integration of mental health/substance abuse and primary care. Evid Rep Technol Assess (Full Rep). 2008;(173):1-362.

26. Bower P, Sibbald B. On-site mental health workers in primary care : effects on professional practice. Cochrane Database Syst Rev. 2000;(3):CD000532. 10.1002/14651858.CD000532

27. Archer J, Bower P, Gilbody S, et al. Collaborative care for depression and anxiety problems. Cochrane Database Syst Rev. 2012;10:CD006525. 10.1002/ 14651858.CD006525.pub2

28. Gillies D, Buykx P, Parker AG, Hetrick SE. Consultation liaison in primary care for people with mental disorders. Cochrane Database Syst Rev. 2015;2015(9): CD007193. 10.1002/14651858.CD007193.pub2

29. Cunningham PJ. Beyond parity: primary care physicians' perspectives on access to mental health care. Health Aff (Millwood). 2009;28(3):w490-w501. 10.1377/hlthaff.28.3.w490

30. Chien AT, Kyle MA, Peters AS, et al. Establishing teams: how does it change practice configuration, size, and composition? J Ambul Care Manage. 2018; 41(2):146-155. 10.1097/JAC.0000000000000229

31. Meyers DJ, Chien AT, Nguyen KH, Li Z, Singer SJ, Rosenthal MB. Association of team-based primary care with health care utilization and costs among chronically ill patients. JAMA Intern Med. 2019;179(1):54-61. 10.1001/ jamainternmed.2018.5118

32. Kathol RG, Degruy F, Rollman BL. Value-based financially sustainable behavioral health components in patient-centered medical homes. Ann Fam Med. 2014;12(2):172-175. 10.1370/afm.1619

33. Hing E, Burt CW. Office-based medical practices: methods and estimates from the National Ambulatory Medical Care Survey. Adv Data. 2007;383:1-15.

34. Muhlestein DB, Smith NJ. Physician consolidation: rapid movement from small to large group practices, 2013-15. Health Aff (Millwood). 2016;35(9): 1638-1642. 10.1377/hlthaff.2016.0130

35. Welch WP, Cuellar AE, Stearns SC, Bindman AB. Proportion of physicians in large group practices continued to grow in 2009-11. Health Aff (Millwood). 2013;32(9):1659-1666. 10.1377/hlthaff.2012.1256

36. Chien AT, Rosenthal MB. A 3D model for value-based care: the next frontier in financial incentives and relationship support. UnitedHealthCare. Published 2019. Accessed Oct 26, 2021. https://newsroom.uhc.com/content/dam/ newsroom/Harvard\%20Report_FINAL_0923.pdf

37. Kroening-Roché J, Hall JD, Cameron DC, Rowland R, Cohen DJ. Integrating behavioral health under an ACO global budget: barriers and progress in Oregon. Am J Manag Care. 2017;23(9):e303-e309.

38. Seifert RW, Love KA. What to know about ACOs: an introduction to MassHealth accountable care organizations. BlueCross BlueShield of Massachusetts Foundation. Published Jul 2018. Accessed Oct 26, 2021. https:// www. bluecrossmafoundation.org/sites/g/files/csphws2101/files/2020-09/ ACO_Primer_July2018_Final.pdf

39. Peikes DN, Reid RJ, Day TJ, et al. Staffing patterns of primary care practices in the comprehensive primary care initiative. Ann Fam Med. 2014;12(2):142149. 10.1370/afm.1626

40. Chien AT, Song Z, Chernew ME, et al. Two-year impact of the alternative quality contract on pediatric health care quality and spending. Pediatrics. 2014;133(1):96-104. 10.1542/peds.2012-3440

41. Chien AT, Schiavoni KH, Sprecher $E$, et al. How accountable care organizations responded to pediatric incentives in the Alternative Quality Contract. Acad Pediatr. 2016;16(2):200-207. 10.1016/j.acap.2015.10.008

42. Chien AT, Conti RM, Pollack HA. A pediatric-focused review of the performance incentive literature. Curr Opin Pediatr. 2007:19(6):719-725. 10.1097/ MOP.Ob013e3282fleb70 
43. Harvey SM, Oakley LP, Yoon J, Luck J. Coordinated care organizations: neonatal and infant outcomes in Oregon. Med Care Res Rev. 2019;76(5):627-642. $10.1177 / 1077558717741980$

44. National Survey of Healthcare Organizations and Systems. Comparative health system performance. Dartmouth College. Accessed Apr 29, 2020. https://sites.dartmouth.edu/coe/nshos/

45. Fraze TK, Brewster AL, Lewis VA, Beidler LB, Murray GF, Colla CH. Prevalence of screening for food insecurity, housing instability, utility needs, transportation needs, and interpersonal violence by US physician practices and hospitals. JAMA Netw Open. 2019;2(9):e1911514. 10.1001/jamanetwork open.2019.11514

46. IQVIA OneKey Databases. IQVIA. Accessed Dec 21, 2021. https://www.one keydata.com/databases

47. O'Malley AJ, Park S. A novel cluster sampling design that couples multiple surveys to support multiple inferential objectives. Health Serv Outcomes Res Methodol. 2020;20(2-3):85-110. 10.1007/s10742-020-00210-y

48. Fisher ES, Shortell SM, O'Malley AJ, et al. Financial integration's impact on care delivery and payment reforms: a survey of hospitals and physician practices. Health Aff (Millwood). 2020;39(8):1302-1311. 10.1377/hlthaff. 2019.01813

49. USDA Economic Research Service. Rural-urban commuting area codes. Published 2020. Accessed May 6, 2021. https://www.ers.usda.gov/data-products/ rural-urban-commuting-area-codes/

50. Centers for Medicare and Medicaid Services. Comprehensive Primary Care Plus. Accessed Oct 26, 2021. https://innovation.cms.gov/innovation-models/ comprehensive-primary-care-plus

51. Center for Health Care Strategies. Psychiatric consultation programs by state. Updated 2018. Accessed Oct 26, 2021. https://www.chcs.org/media/ Psychiatric-Consultation-Programs_FINAL-030818.pdf
52. Health Resources and Services Administration. Leadership Education in Adolescent Health (LEAH) fact sheet. Published 2016. Accessed Oct 26, 2021. https://mchb.hrsa.gov/training/documents/fs/factsheet-LEAH.pdf

53. Frank RG, Beronio K, Glied SA. Behavioral health parity and the Affordable Care Act. J Soc Work Disabil Rehabil. 2014;13(1-2):31-43. 10.1080/1536 710X.2013.870512

54. Lewis VA, Colla CH, Tierney K, Van Citters AD, Fisher ES, Meara E. Few ACOs pursue innovative models that integrate care for mental illness and substance abuse with primary care. Health Aff (Millwood). 2014;33(10):18081816. 10.1377/hlthaff.2014.0353

55. Newton HE. Integrating Mental Health and Primary Care Under New Payment Models. Dissertation. Darmouth College; 2020. Accessed Oct 26, 2021. https://www.proquest.com/openview/b6b8de50cb85792e1afa7d6b2479 $95 \mathrm{a} 2 / 1$ ?pq-origsite $=$ gscholar $E \mathrm{cb}=18750 \varepsilon$ diss $=y$

56. Conroy K, Samnaliev M, Cheek S, Chien AT. Pediatric primary care-based social needs services and health care utilization. Acad Pediatr. 2021;S1876S2859(21):00013-9. 10.1016/j.acap.2021.01.012

57. Song Z, Ji Y, Safran DG, Chernew ME. Health care spending, utilization, and quality 8 years into global payment. N Engl J Med. 2019;381(3):252-263. 10.1056/NEJMsa1813621

58. MCWilliams JM, Hatfield LA, Landon BE, Hamed P, Chernew ME. Medicare spending after 3 years of the Medicare Shared Savings Program. N Engl J Med. 2018;379(12):1139-1149. 10.1056/NEJMsa1803388

59. National Association of ACOs. Medicare state ACO activities. Published 2021. Accessed Oct 26, 2021. https://www.naacos.com/medicaid-acos

60. Wasserman RC, Varni SE, Hollander MC, Harder VS. Change in site of children's primary care: a longitudinal population-based analysis. Ann Fam Med. 2019;17(5):390-395. 10.1370/afm.2416 